\title{
Os conflitos nos desdobramentos de uma intervenção em clínica da atividade em contexto escolar
}

\author{
Ermelinda Barricelli ${ }^{1}$ \\ Katia Diolina² \\ Daniela Dias dos Anjos ${ }^{3}$
}

\section{Resumo}

Este artigo discute os conflitos desencadeados nos desdobramentos de uma intervenção que ocorreu de 2014 a 2020 no contexto da Educação Infantil. A intervenção se desenvolveu, inicialmente, com quatro Professores de um Centro de Educação Infantil - CEI, que atende crianças de 0 a 3 anos, da região periférica da Cidade de São Paulo, entre 2014 e 2015. Em momentos posteriores, outros profissionais (professores e gestores) demandaram a continuidade da intervenção. Desta forma, em um primeiro momento, apresentou-se a perspectiva teórica e metodológica que orienta o estudo e as análises, e discutiram-se os desdobramentos deste processo de intervenção com foco nos conflitos vividos pelos profissionais no exercício de sua atividade de trabalho. A partir das análises, constatou-se o quanto o trabalho dos professores e dos gestores sofre com conflitos de dimensões distintas: pessoais, impessoais, interpessoais e, particularmente, transpessoais. Conflitos que assinalam os atritos entre o que se quer se fazer e o que se faz; entre o que se pensa que faz e não se faz; entre o que se deve fazer e o que se pode fazer; entre o que o colega faz e o que se necessita fazer. Em síntese, o contexto da Educação Infantil é um fértil campo de investigação da atividade de trabalho.

Palavras-chave: Clínica da Atividade, Autoconfrontação, Trabalho Docente.

\section{Unfolded intervention conflicts in a clinical activity in a school environment}

\begin{abstract}
This paper discusses the conflicts brought about by an unfolding intervention that took place during the period of $2014-2020$ in the context of Early Childhood education. The intervention initially involved 4 homeroom teachers in a CEI (Centro de Educacao Infantil - Early Childhood Center) whose students' ages ranged from 0 - 3-year-olds, located in the outskirts of São Paulo City, between 2014 and 2015. Later on, other professionals (teachers and managers) requested the continuity of this intervention. Therefore, the first step focused on introducing the theoretical perspective as well as the methodology that guided this study and its analyses. It was also discussed the unfolding results from this intervention process with a focal point on the conflicts that the professionals went through while on duty. Based on these analyses, it was observed the amount of personal affliction undergone by teachers and managers circling distinct dimensions: personal, interpersonal and, particularly, transpersonal. Conflicts that highlight discordance between what one wants to do and what is done; between what one thinks it is done but it is not done; between what must be done and can be done; between what a colleague does and what is needed to be done. Summing up, the context of Early Childhood Education is an abundant field of investigative working activity.

Keywords: Clinic of Activity; Self Confrontation; Teaching Work.
\end{abstract}

\footnotetext{
${ }^{1}$ Universidade São Francisco, Atibaia, ermelinda.barricelli@usf.edu.br

${ }^{2}$ SME - Prefeitura Municipal de Itatiba, katidio@gmail.com

${ }^{3}$ Universidade São Francisco, Jundiai-SP, daniela.anjos@usf.edu.br
} 


\section{Introdução}

Este artigo ${ }^{4}$ aborda os conflitos desencadeados nos desdobramentos de uma intervenção em Clínica da Atividade que ocorreu de 2014 a 2020 no contexto da Educação Infantil.

Neste trabalho, entendemos a intervenção como um processo que consiste em assumir o pesquisador atuante, participante da situação de pesquisa, do diálogo que se estabelece, assumindo o "outro" como sujeito da/na investigação. O pesquisador, portanto, integra e orienta o diálogo com base no conceito de atividade dirigida como unidade de compreensão e explicação das situações de trabalho. Nesse processo, pesquisador e pesquisado afetam-se, transformandose. Dessa forma, os pressupostos que ancoram essa metodologia se encontram nas elaborações teórico-metodológicas de Vigotski (2001) e de Bakhtin (2003) - mais particularmente, em seus modos de conceber o desenvolvimento humano e o estatuto da linguagem nesse processo.

Particularmente, a proposta da intervenção iniciou em 2013 em um Centro de Educação Infantil - CEI localizado no bairro Cidade Tiradentes, extremo Oeste da cidade de São Paulo. O CEI atende cerca de 250 crianças com idade entre 0 e 4 anos e 11 meses e é uma instituição bem equipada, com infraestrutura adequada para o atendimento de crianças pequenas.

Foram realizadas, em 2014 e 2015, autoconfrontações simples (ACS), primeiramente; e cruzadas (ACC), em seguida. O processo de intervenção começou com a observação e com o acompanhamento dos Professores em situação de trabalho. Posteriormente, foram realizados encontros para explicitação da proposta e consequente convite para participação. Quatro Professores se voluntariaram para participar desse primeiro momento. As autoconfrontações (simples e cruzadas) revelaram conflitos próprios desse segmento, o que melhor detalharemos nas discussões das análises dos debates suscitados nas entrevistas de ACS e/ou nas entrevistas de ACC.

Reforçamos que, inicialmente, quatro Professores se engajaram na intervenção, entre os anos de 2014-2015, mas, em um segundo momento, outros Professores, não envolvidos diretamente no processo de filmagem e discussão da prática, começaram a se autofilmar, com o

\footnotetext{
${ }^{4}$ Oriundo da apresentação realizada no IV Colóquio Internacional da Clínica da Atividade (CICA), que ocorreu na Universidade São Francisco - Câmpus Bragança Paulista em 2019.
}

Periódico Horizontes - USF - Itatiba, SP - Brasil - e021040 
intuito de observar-se em situação de trabalho. Essas imagens foram postas em debate em duas reuniões com o coletivo de Professores do CEI, o que culminou em adesão de outros participantes e intensificou as discussões.

Nesse processo de apropriação e envolvimento da equipe escolar com a metodologia, houve um terceiro movimento, que se iniciou com a transferência da Diretora para uma outra unidade - uma Escola Municipal de Educação Infantil - EMEl que atende crianças de 4 a 5 anos. Com essa mudança da direção para a EMEI, uma das quatro Professoras engajadas na intervenção inicial na CEI foi convidada a assumir o cargo de Assistente de Direção (Vice). Assim, Diretora e Vice, na nova instituição, retomaram a intervenção - centrada nos conflitos da equipe gestora em novo contexto - com as autoconfrontações, o que vem se desenvolvendo desde 2018.

Desta forma, neste artigo, discutiremos os conflitos revelados pelas intervenções sobre o trabalho docente no exercício de funções distintas: Professor e gestor. Ressaltamos que todos os profissionais têm como elemento comum a formação de pedagogo, mas cumprem funções diversas e experimentam cargos distintos, em contextos também diferentes. É interessante levantar os desafios impostos nas atividades descritas, seja para destacar as diferenças, seja para constatar as semelhanças.

Para tanto, neste artigo, em um primeiro momento, apresentaremos a perspectiva teórica e metodológica que orienta o estudo e as análises. Em seguida, detalharemos o contexto da educação infantil e os conflitos que fazem parte desta atividade, para, então, problematizarmos os desdobramentos do processo de intervenção com foco nos conflitos vividos pelos profissionais no exercício de suas atividades de trabalho.

\section{Clínica da atividade}

Este estudo se ancora na perspectiva histórico-cultural (VIGOTSKI, 2001; 2003, 2009); e nos referenciais sobre atividade de trabalho da Clínica da Atividade (CLOT, 1999, 2008, 2014; CLOT; FAÏTA, 2016; CLOT et al., 2001). 
Desses referenciais, destacamos alguns conceitos para discussão. Entre eles, a compreensão da atividade de trabalho como sendo uma atividade triplamente dirigida. Para Clot (2006, p.97), a atividade de trabalho, "é dirigida não só pelo comportamento do sujeito ou dirigida por meio do objeto da tarefa, mas também dirigida aos outros... Ela é sempre resposta à atividade dos outros, eco de outras atividades. Ocorre numa corrente de atividades que constitui um elo". Em outros termos, a atividade de trabalho consiste numa relação dinâmica entre três polos principais: o profissional; o ambiente; e os demais, que estão direta ou indiretamente implicados na atividade, além de ela ser realizada por diferentes instrumentos técnicos e/ou simbólicos. Nessa relação, a atividade forma-se e transforma-se continuamente, sendo sempre única, todavia múltipla em possibilidades. Esse processo é importante, porque a Clínica da Atividade tem por objetivo a transformação das situações de trabalho, concebendo os trabalhadores como os protagonistas dessa transformação (CLOT, 2010).

A proposta metodológica pressupõe a descoberta de novas formas possíveis da ação, baseando-se na ideia de que a atividade realizada não é senão uma dentre muitas outras possibilidades de realização. De acordo com Clot (2005), fazendo referência a Vigotski, o homem é pleno, a cada minuto, de possibilidades que, embora não realizadas, não são menos reais. $E$, por ser um universo de possibilidades, a atividade realizada consiste nas ações vencidas, escolhidas, postas em cena no curso da prática. Todavia, se houve uma escolhida, há também as atividades impedidas, suspensas, contrariadas que, segundo Clot (2005), continuam agindo nos sujeitos e devem ser consideradas na análise do trabalho.

Embora as ações exercidas (ou não) integrem e atuem na configuração da atividade de trabalho de todo profissional, as escolhas, ao efetuar uma ação ou mesmo excluir outra, não são algo que se possa observar diretamente. Daí a importância dos métodos indiretos de análise do trabalho em Clínica da Atividade: autoconfrontação simples e cruzada e instrução ao sósia. Tais métodos têm por objetivo permitir aos sujeitos transformar a experiência vivida em objeto de uma nova experiência. A proposta é ir ao encontro de outras realizações possíveis, desenvolver novos objetos e destinatários, o que possibilita o desenvolvimento da atividade. É essa a ideia perseguida na criação dos métodos em Clínica da Atividade.

Periódico Horizontes - USF - Itatiba, SP - Brasil - e021040 
Esta metodologia busca compreender como se organiza a transformação da ação, ao mesmo tempo em que propõe um meio de operar essa alteração. Uma intervenção em clínica da atividade envolve pelo menos três momentos: (i) observação da situação de trabalho, (ii) entrevistas de confrontação e (iii) retorno ao coletivo.

$\mathrm{Na}$ autoconfrontação simples, o trabalhador assiste às cenas videogravadas de seu trabalho junto com um pesquisador. Nesse momento, as reflexões já iniciadas por ocasião da auto-observação são mobilizadas. Na autoconfrontação simples, o sujeito torna-se um observador externo de sua própria atividade, “[...] em posição exotópica a respeito de seu trabalho e face a escolhas ou dilemas que ele redescobre na sua atividade, o que era operação incorporada e resposta automática torna-se questão" (CLOT, 2010, p.226).

No diálogo que ele deve assumir com o pesquisador e para sustentar essa troca sobre os mistérios de sua atividade, geralmente, o sujeito busca 'não ficar só'. Em outros termos, para sustentar aquilo que é difícil de dizer na autoconfrontação simples, muitas vezes, o trabalhador convoca o coletivo, ou seja, não fala só em primeira pessoa, usando "eu", mas traz um "nós-a gente" em seu enunciado - "a gente faz assim". O sujeito é visto não somente com seus próprios olhos - observação interior - mas com os olhos de um observador exterior que não é mais somente o pesquisador, mas o métier, ou ainda, o coletivo. Na busca por justificar um dado modo de realizar a atividade, o sujeito dispõe da história coletiva do métier, que pode lhe fornecer elementos para explicar o que se vê fazendo na tela.

A autoconfrontação cruzada tem o objetivo de colocar em discussão diferentes pontos de vista e concepções sobre os modos de realizar uma mesma atividade. Dois trabalhadores irão juntos observar uma mesma videogravação de um colega. Ao comparar suas maneiras de fazer ou de dizer na situação observada, eles rapidamente encontram diferenças. O “a gente faz assim” torna-se objeto de controvérsia no diálogo com outro trabalhador, que frequentemente diz "não é bem assim, faço de outro jeito".

Na autoconfrontação cruzada, há uma mudança de destinatário: agora não se fala mais só ao pesquisador, mas ao colega de trabalho. Essa mudança de destinatário modifica a análise. A autoconfrontação cruzada tem, portanto, o objetivo de organizar a controvérsia e com isso possibilitar o desenvolvimento do métier.

Periódico Horizontes - USF - Itatiba, SP - Brasil - e021040 
Desse modo, o coletivo de trabalho pode se sentir um pouco menos prisioneiro das verdades do momento, podendo ser colocado em questão. Os trabalhadores, juntos, podem encontrar novos modos de agir; já que o objetivo é reencontrar, a partir de imagens do que foi feito e do que os profissionais disseram do que fizeram, aquilo que poderá ser feito (CLOT, 2010). A proposta de autoconfrontação cruzada traz implicada a noção de desenvolvimento de Lev Vigotski. Clot (2010) considera que o fato de o trabalhador pensar e falar sobre seu trabalho em um novo contexto e lidar com as controvérsias e as diferenças entre modos de fazer pode vir a desenvolver a atividade e o próprio sujeito, entendendo aqui desenvolvimento como processo de transformação, de acordo com Lev Vigotski.

\section{Conflitos próprios do métier}

Antes de discutirmos questões relativas aos conflitos da profissão docente na Educação Infantil, é importante detalhar sobre esse contexto de trabalho que tem história e peculiaridades próprias. Características singulares de um métier, que nos ajudam, inclusive, a melhor compreender os conflitos que estão implicados no agir docente.

Sendo assim, questionamos sobre o que significa ser Professor na Educação Infantil no Brasil e sobre como ser socialmente valorizado atuando no ensino infantil.

Para responder a essas questões, retomamos a história da institucionalização do ensino na Educação Infantil no Brasil, que se deu a partir do século XX, particularmente, nos anos 70, quando as mulheres passaram a atuar massivamente no mercado de trabalho, o que promoveu, segundo Barricelli (2012, p.17), um "entendimento assistencialista sobre a criança". Tal característica tinha um enfoque maior em creches que, na época, foram criadas para "crianças de baixa renda e tinha, também, a finalidade de livrar essas crianças do risco de morte que a pobreza Ihes impunha" (BARRICELLI, 2012, p.17). Segundo a autora, as crianças de origem mais elevada não utilizavam as creches, já que elas eram atendidas em instituições denominadas préescolas, com um caráter mais recreativo, em prol do desenvolvimento afetivo-cognitivo. Dessa forma, a educação infantil originou-se com base em dois enfoques distintos: o cuidar e o educar. Ambos ainda atuam nas bases estruturais, nas raízes da Educação Infantil, fomentando 
discussões acerca das consequências e dos limites impostos por tais ações e noções, inclusive a respeito do papel do Professor, que pode ser considerado e avaliado como cuidador ou educador.

Particularmente, os anos 70 e 80 foram fundamentais para a origem e a institucionalização da Educação Infantil, mas foi ao final dos anos 80 e início dos anos 90 que novas leis e diretrizes atuaram na configuração e na orientação quanto aos modos de agir e de pensar o contexto da creche e da pré-escola.

Em 1988, a Constituição Federal instituiu a Educação Infantil como direito inviolável de crianças de zero a 5 anos de idade que poderiam ser matriculadas em escolas públicas (artigo 205), outorgando, assim, a oferta e a criação de creches e pré-escolas em todo território nacional (artigo 208) de modo gratuito e de qualidade, com condições de acesso, permanência e pleno aproveitamento das oportunidades de aprendizagem (artigo 206).

Embora a Constituição Federal seja de suma importância para a institucionalização da Educação Infantil no Brasil, o caráter assistencialista ainda se manteve, já que tal contexto educacional foi posto sob a supervisão da Secretaria de Assistência Social (BARRICELLI, 2012). Entretanto, foi por meio da Lei de Diretrizes e Bases da Educação ( $N^{\circ} .9 .394$ de 1.996) que a Educação Infantil se tornou mais um braço, ou melhor, tornou-se um dos pilares da Educação Básica Nacional e passou a ser de responsabilidade das Secretarias da Educação.

Embora esse salto seja importante para a Educação Infantil, ela ainda continua dividida em dois segmentos distintos atualmente: (i) creche, com crianças de zero a 3 anos e 11 meses; (ii) e pré-escola, com crianças de 4 a 5 anos e 11 meses (BRASIL, 2018). Barricelli (2012) esclarece que essa dicotomia contribui para manter a polaridade no processo de ensino e aprendizagem das crianças, a relação cuidar-educar, o que, inclusive, tem implicações diretas sobre o papel do Professor e de sua valorização social. Isso ocorre, uma vez que o profissional transita tanto na esfera do assistencialismo (cuidador) quanto na esfera do ensino- aprendizagem como aquele capaz de tomar decisões didático-pedagógicas em prol do desenvolvimento integral das crianças. Em outros termos, o papel do Professor na Educação Infantil deveria se configurar em razão das especificidades: de educar, de formar, de ensinar, de contribuir com o desenvolvimento. 
Em busca de uma maior valorização do estatuto de Professor, a LDB (9394/96) exige o Ensino Superior daqueles que atuam na Educação Infantil, enquanto profissionais pedagogos, bem como a promoção e a legitimação de documentos oficiais que normatizam e regularizam as concepções e as práticas no contexto educacional infantil.

Nesse sentido, no final dos anos 90, os Referenciais Curriculares Nacionais da Educação Infantil ${ }^{5}$ trouxeram contribuições acerca dos caminhos, dos modos possíveis de agir e de pensar o contexto da creche e da pré-escola, já que havia uma condição de reformas educacionais e de embates teórico-práticos a respeito do processo de ensino e aprendizagem, particularmente, em torno do denominado 'ensino tradicional' (BUNZEN, 2011). Sendo assim, os Referenciais Curriculares Nacionais emergem com o intuito de orientar - como referências, como parâmetros, como caminhos possíveis de trilhar na Educação Infantil. Particularmente, Barricelli $(2007,2012)$ esclarece que os RCNEI's, primeiro e único documento prescritivo de orientação sobre a educação das crianças nos anos 90, tornaram-se essenciais e amplamente divulgados.

Passados 20 anos da promulgação dos RCNEl's em 1997, a Base Nacional Comum Curricular (BRASIL, 2018) do ensino infantil foi outorgada e instituída em prol da legitimação e da normatização do trabalho na Educação Básica, incluindo, portanto, a educação infantil. Vale ressaltar que esses dois documentos (BNCC e RCN) são os principais, de ordem nacional, que visavam, e visam, à orientação das ações acerca do trabalho na Educação Infantil.

A Base Nacional Comum Curricular, portanto, assume o objetivo de nortear o trabalho do Professor em relação ao conteúdo básico do currículo nacional, às competências e às habilidades a serem desenvolvidas no processo de ensino e aprendizagem. Trata-se de um documento oficial recém-outorgado, que na sua última versão, em 2018, incluiu as orientações para o Ensino Médio. O documento (BRASIL, 2018) prescreve em nível nacional os conhecimentos fundamentais para toda a Educação Básica: (i) Ensino Infantil; (ii)Ensino Fundamental (anos iniciais [1음 ao ] e anos finais [6으 ao 9o ano]); e (iii) Ensino Médio, bem como defende que o par educar e cuidar reúne duas vertentes indissociáveis e devem ser mantidas no processo educativo

\footnotetext{
${ }^{5}$ Optamos, neste trabalho, por apontar somente os dois documentos oficiais do MEC: Referenciais Curriculares Nacionais para Educação Infantil (BRASIL, 1997) e Base Nacional Comum Curricular (BRASIL, 2018) dada a importância em nível nacional, mas estamos cientes de que muitos documentos completaram esses dois, especialmente nos segmentos estaduais e municipais.
}

Periódico Horizontes - USF - Itatiba, SP - Brasil - e021040 
da infância. Conforme a BNCC, isso ocorre porque, no contexto creche e pré-escola, importa "acolher as vivências e os conhecimentos construídos pelas crianças no ambiente da família e no contexto de sua comunidade, e articulá-los em suas propostas pedagógicas", em favor de maior ampliação das experiências, dos conhecimentos e das habilidades das crianças (BRASIL, 2018, p.36). A criança é concebida como um ser que observa, questiona, levanta hipóteses, conclui, faz julgamentos e assimila valores, além de construir e de apropriar-se dos mais diversos conhecimentos. A partir dessa compreensão existe, consequentemente,

a necessidade de imprimir intencionalidade educativa às práticas pedagógicas na Educação Infantil, tanto na creche quanto na pré-escola. Essa intencionalidade consiste na organização e proposição, pelo educador, de experiências que permitam às crianças conhecer a si e ao outro e de conhecer e compreender as relações com a natureza, com a cultura e com a produção científica, que se traduzem nas práticas de cuidados pessoais (alimentar-se, vestir-se, higienizar-se), nas brincadeiras, nas experimentações com materiais variados, na aproximação com a literatura e no encontro com as pessoas. Parte do trabalho do educador é refletir, selecionar, organizar, planejar, mediar e monitorar o conjunto das práticas e interações, garantindo a pluralidade de situações que promovam o desenvolvimento pleno das crianças. Ainda, é preciso acompanhar tanto essas práticas quanto as aprendizagens das crianças, realizando a observação da trajetória de cada criança e de todo o grupo - suas conquistas, avanços, possibilidades e aprendizagens. Por meio de diversos registros, feitos em diferentes momentos tanto pelos Professores quanto pelas crianças (como relatórios, portfólios, fotografias, desenhos e textos), é possível evidenciar a progressão ocorrida durante o período observado (BRASIL, 2018, p.38).

Como se constata nesse excerto, o trabalho do Professor consiste numa infinidade de ações, práticas e teorias que o tornam um fenômeno complexo, multidimensional, pois ocorre em contextos distintos, em razão de diferentes objetivos, dos recursos e das pessoas envolvidas ou não. Em outros termos, trata-se de uma atividade situada, realizada por um profissional que dispõe de dimensões físicas, psíquicas, emocionais, metabólicas, cognitivas, que se liga - e se desliga - a uma rede discursiva complexa, que envolve direta e indiretamente diferentes interlocutores (alunos, pais, responsáveis, funcionários, colegas, gestores, supervisores, prescritores) e que atua a partir dos recursos, dos objetivos e das condições de que dispõe ou não. Essa perspectiva é importante porque permite contestar e negar a cristalização de 
conhecimentos e de modos de agir, a fim de ultrapassar a zona de conforto e possibilitar a problematização de "zonas proximais" de conhecimentos, "ver com outros olhos" (FABRíCIO, 2006, p.52).

É nesse sentido que discutimos a respeito dos conflitos do métier enquanto conjunto de recursos em prol do desenvolvimento e da transformação do agir, da atividade de trabalho do Professor. Isso é possível porque, segundo Clot (2007, p.99), "a atividade dirigida é uma arena, ou melhor, o teatro de uma luta [...] em que o desenvolvimento alcançado pela atividade do sujeito que trabalha é um sistema de ações que venceram".

O trabalho, portanto, constitui-se de tríplice relação, em que o trabalhador (o profissional) realiza uma atividade de trabalho, mas, para isso, ele precisa organizar o meio/ambiente (o objeto) para exercer a atividade, numa relação direta e indireta com diferentes pessoas, colegas de profissão, chefes, clientes (o outrem), e essa relação tríade é sempre mediada por instrumentos materiais ou simbólicos, como a linguagem. É nessa relação, portanto, que os embates, os conflitos são postos em cena, e os sujeitos buscam "ultrapassar as contradições existentes no interior desses três polos de determinação, bem como entre eles" (CLOT, 2007, p.99). É nesse sentido que a atividade dirigida se torna a "célula viva, o berço de uma ação vinculada aos conflitos que a fizeram nascer, onde se cruzam mecanismos de agudização e inibição" (CLOT, 2007, p.101). O conflito é, portanto, a fonte da atividade dirigida, já que "cada um dos três polos da tríade da atividade traz em si conflitos que são fatores de incitação para cada um dos outros" (CLOT, 2007, p.101).

Isso é importante porque o processo de desenvolvimento humano ocorre por meio da vivência dos conflitos que se estabelecem no hiato, na distância entre o trabalho prescrito e o trabalho efetivamente realizado. Na relação entre trabalho prescrito e realizado, abre-se uma lacuna entre o possível de ser realizado e o que se espera na sua realização. Em outros termos, a ação empregada pelo sujeito profissional durante o exercício de seu trabalho é uma prática "mais ou menos conflitual para regular essa distância [...] e construir recursos que contribuirão para seu desenvolvimento profissional e pessoal" (AMIGUES, 2004, p.40). É nesse processo de regulação (entre prescrito e realizado) que ocorre o trabalho real, isto é, a regulagem, a readaptação de normas, de situações, de recursos, em que muitas ações são realizadas e outras 
não, sendo todas elas elementos do trabalho real. Nas palavras de Clot (2010, p.103), trata-se "do que se tenta fazer sem ser bem-sucedido - o drama dos fracassos - o que desejaria ou poderia ter feito e o que se pensa ser capaz de fazer noutro lugar".

O trabalho real, portanto, extrapola o que é visível, o que é observável no interior de uma atividade, o que exige uma metodologia indireta de análise do trabalho, como a autoconfrontação. "Trata-se de uma dimensão psicológica da atividade que considera as potencialidades, mas também os impedimentos ou as amputações dos gestos dos indivíduos" (LOUSADA; DANTAS-LONGI, 2014, p.150). Esses embates, esses conflitos podem se tornar "motores para a tomada de consciência dos sujeitos quanto a sua atividade e consequentemente para seu desenvolvimento e, por outro lado, [...] traços desse processo de tomada de consciência podem ser encontrados na análise da linguagem" (LOUSADA; DANTAS-LONGI, 2014, p.148).

Por meio da autoconfrontação cruzada, segundo Clot (2007), a atividade dirigida passa por três momentos distintos: um, de concepção partilhada das situações a serem examinadas; outro, de produção das filmagens; e, por fim, o último, de análise e coanálise das situações filmadas. Nesse último momento, trata-se de uma "filtragem da experiência profissional posta em discussão", em que se estabelece "um ciclo entre aquilo que os trabalhadores fazem, aquilo que eles dizem daquilo que eles fazem e, por fim, aquilo que eles fazem daquilo que eles dizem" (CLOT, 2007, p.136).

É, portanto, nesse momento, que o diálogo se torna oxigênio da atividade dirigida, pois possibilita o fazer de diferentes maneiras. Conforme Clot (2010, p.136), a atividade respira, a pessoa pode reviver, dizer, enfrentar os conflitos, transformar a atividade "em si" e "para si".

E essa transformação ocorre, particularmente, em razão do métier em que estamos inseridos. No trabalho do Professor da Educação Infantil, fica claro o conflito entre as atribuições de um cuidador e de um educador, tendo em vista as noções que possamos assumir em relação a esses termos. Além dessas noções, outras atribuições, entre tantas que pesam dia após dia, são também exigidas, ou mesmo questionadas, como: ser amoroso, o que é ser profissional; ser reconhecido pelos alunos; realizar o trabalho com eficiência, não causar mal-estar no coletivo, seguir as prescrições.

Periódico Horizontes - USF - Itatiba, SP - Brasil - e021040 
Mas esse peso pode ser mais tênue, se assumirmos a complexidade da atividade docente quanto aos papéis dos demais, que integram e participam, direta ou indiretamente, do trabalho do Professor, como: o colega de trabalho, a direção, o vice, a coordenação, os alunos, os pais etc. Há ainda um outro elemento não visível: as leis, as políticas educacionais, as teorias pedagógicas, as imagens representativas, as expectativas, o coletivo de trabalho etc. É nesse sentido que "o outro pode estar ausente, sem, contudo, deixar de estar... implicado" (CLOT, 2006, p.100).

O ideal, para equalizar essas forças implicadas na atividade, é compreender a importância do coletivo de trabalho e do trabalho coletivo; pois compreender que não se está sozinho é reconhecer-se naquilo que se realiza e em que os demais legitimam. Segundo Diolina (2016, p.70), "o coletivo constitui o indivíduo, bem como se desenvolve nas trocas exteriores com outrem, num acordo dialógico das possibilidades a viver e a serem vividas, dos desafios a vencer e os vencidos." Existe, portanto, uma conjugação dos tempos passado e futuro num presente em curso, em que o gênero profissional permeia, contribui e se transforma. Nas palavras de Clot (2010, p.176), “o coletivo de trabalho deve tornar-se meio para o desenvolvimento da ação de cada um".

Isso ocorre porque, de acordo com Clot (2017), o ofício comportaria quatro dimensões: impessoal (prescrição); pessoal; interpessoal e transpessoal. Nas palavras do autor, a atividade de trabalho.

é primeiramente o gesto pessoal próprio de cada um que nos faz dizer que alguém tem o métier. Mas, no trabalho, não é só. $O$ gesto pessoal é sempre dirigido aos colegas destinatários dos esforços consentidos. O métier é nesse aspecto interpessoal... Ele não é todo inteiro no presente das atividades compartilhadas na situação. Estas precisam de antecedentes que permitam se colocar no diapasão da ação: é a história e a memória coletiva que dão a cada um a garantia para agir no presente e 'ver chegar' o futuro. Essa memória é transpessoal, ninguém é seu proprietário. Disponível a todos quando ela existe, ela atravessa as gerações e cada profissional individualmente. É o teclado coletivo dos gestos e das palavras, sobre o qual cada sujeito pode tocar sua pequena música, o gênero profissional a ser estilizado por cada um... Além disso, o métier não é instituído somente na memória coletiva transpessoal. Ele existe também, impessoal, registrado nas funções oficiais prescritas. É uma carreira, uma aposentadoria, deveres, status, formação, critérios de avaliação e de recrutamento, indicadores padronizados de performance, enfim um outro mundo além daquele da atividade em situação ou da história coletiva implícita. Ele é depositado nos recursos humanos e no mercado de trabalho. É a

Periódico Horizontes - USF - Itatiba, SP - Brasil - e021040 
aparelhagem mais afastada da atividade concreta. No contato com esse registro, cada um se sente substituível (CLOT, 2017, p.20).

Há tensões em todos os registros, pois o "métier reúne - nas discordâncias criativas ou destrutivas - esses quatro registros: impessoal, transpessoal, interpessoal e pessoal" (CLOT, 2017, p.20). O autor dá destaque à dimensão transpessoal, que pode trazer vida e renovação ao ofício.

\footnotetext{
Um métier sem resposta transpessoal pode degenerar um face a face raivoso entre um exercício pessoal solitário e injunções impessoais fictícias. Uma verdadeira despersonalização do trabalho se segue. É no defronte dessa dissociação ameaçadora que se porta a ação em clínica da atividade [...] (CLOT, 2017, p.21).
}

Em outros termos, as dimensões “estão estruturalmente ligadas, em tensão, em conflito, e a fluidez da relação entre elas depende das questões de saúde e da eficiência do trabalho: tudo está ligado; ou ao menos deveria estar, para que a vitalidade profissional não se dissipe"6 (KOSTULSKI et al., 2011, p.134). O jogo entre essas instâncias nutre a criatividade na atividade de trabalho, mas o excesso da instância impessoal ou a necrose da transpessoal conduzem o indivíduo ao isolamento profissional, num conflito direto com as normas, com as regras (KOSTULSKI et al., 2011). Daí nosso interesse em compreender como essas dimensões atuam na atividade de Professores e de gestores, em busca de melhor compreender os papéis atribuídos a elas no contexto educacional, conforme configurado nos textos.

\section{Desdobramentos da intervenção}

A análise do trabalho desencadeou diferentes situações cotidianas da prática dos Professores e dos gestores, provocando diferentes debates.

6 "Ces quatre instances sont structurellement liées, en tension, en conflit, et de la fluidité de leurs rapports dépendent les questions de santé et d'efficacité au travail : tout est lié ; ou du moins devrait l'être pour que la vitalité professionnelle ne se dissipe pas" (KOSTULSKI et al., 2011, p.134).

Periódico Horizontes - USF - Itatiba, SP - Brasil - e021040 
A partir da análise da autoconfrontação simples com o Professor Mario, observando sua atuação com as crianças em um jogo da memória, ele pausa o vídeo e explicita para a interveniente que atua na profissão, recorrendo a sua experiência de mais de 10 anos como Professor, o que lhe permite aliar prática com teoria, conforme o excerto a seguir.

Mario: E é assim, uma coisa que eu percebo de mim, por exemplo, é que eu sou assim. Tudo isso é planejado? Não! Mas uma coisa que eu percebo é que eu sou ótimo no improviso (risos). E é isso mesmo, uma coisa que a gente aprendeu nos cursos que a gente fez, é o seguinte, você tem que acabar com a brincadeira, antes que a brincadeira acabe. Você não pode deixar a brincadeira acabar por si, perde a graça, né?, mas você tem que vir nessa inovação, renovando, atendendo, no caso, aí, correspondendo às expectativas das crianças, né?

Interv: E sempre foi assim?

Mario: (rindo) Não... Não... Isso veio com o tempo, acho que é a experiência...

A Professora Chris, ao observar sua imagem gravada nas discussões realizadas na ACS, espanta-se com sua postura, que Ihe parece brava demais para o segmento da Educação Infantil. Surpreendida, a Professora observa:

Chris: Eu sou uma Professora brava... Eu tenho uma postura brava... Interv.: E você não sabia?

Chris: Não... eu me escuto isso. E acho que não é real, imagina! É tão engraçado porque a postura corporal é uma, mas o que eu estou pensando e estou sentindo é outra [coisa] eu me choco quando ficam 'você é brava Chris' 'você é brava Chris'... e eu sou (fala apontando o vídeo) uma postura assim.... E tão engraçado, né?

O conflito vivenciado pela Professora Chris repercute na Instituição, instigando os colegas, e, assim inspirados pelos colegas, os demais Professores do CEI, que não estavam envolvidos diretamente na intervenção, começam a se filmar. Os registros, que inicialmente surgiram como uma curiosidade particular, contagiam e se tornam uma prática no CEl. Esses Professores aceitaram o convite de mostrar suas filmagens para o coletivo e de colocar em debate o que descobriram. Nesse processo, foram realizados cinco encontros, em que os Professores mostram suas autofilmagens e as trocas ilustram o que significou esse momento da intervenção:

Periódico Horizontes - USF - Itatiba, SP - Brasil - e021040 
Interv.: Primeiro, como foi filmar, de modo geral, vocês gostaram, ficaram espantadas, como foi a experiência de se filmar?

Rose: Eu gostei. Achei bem legal. Eu nunca tinha filmado, eu sempre tive vontade de filmar, eu dizia, qualquer dia vou filmar minha classe, qualquer dia vou filmar minha prática, mas nunca tive oportunidades, assim, tal, né? Daí, quando eu filmei, eu disse: 'gente, como é legal, como é bom você ver como é seu diálogo com as crianças', entendeu? Daí, você fala assim, 'nossa! Eu fico o tempo todo falando, 'meu amor', 'meu bem', 'não, meu anjo', 'oi, meu príncipe, bom dia', nossa, como que eu sou! Será que estou certa agindo dessa maneira? Será que estou errada?' Fiquei me questionando por que eu trato as crianças tão carinhosamente, se é legal ou se não é.

Interv.: Você viu que você faz isso?

Rose: É, eu vi...

As trocas verbais apresentadas nos mostram como os Professores entendem o métier da Educação Infantil. Mário mostra a importância da experiência e do estudo. Já Chris e Rose confrontam formas opostas de atuar com as crianças: a primeira espanta-se com sua cara brava, revelando não considerar adequada essa forma de atuar com crianças pequenas; por outro lado, Rose se inquieta com a forma infantilizada com que trata as crianças. Afinal, como deve atuar o profissional de Educação Infantil? Vemos nesse ponto um conflito próprio do métier de Educação Infantil, particularmente, no que tange aos modos de agir, ao aspecto transpessoal (CLOT, 2017) da profissão. Existem prescrições, bem como autoprescrições que provocam, que colocam em atrito o que "se deve fazer" com o que "se faz". Esse atrito é ainda reforçado pela voz do coletivo, dos colegas, em que os modos de fazer são avaliados e podem ou não ser legitimados. (BARRICELLI; ANJOS, 2020).

Bakhtin (1992) nos lembra que significação existe como capacidade potencial de construir sentido, própria dos signos linguísticos e das formas gramaticais da língua. É o sentido que esses elementos historicamente assumem, em virtude de seus usos reiterados. Retomando a história do segmento, vamos entender que a Educação Infantil se constituiu marcada pela dicotomia clássica entre o cuidar e o educar, em que as instituições infantis no Brasil foram criadas, com uma concepção filantrópica, custodial e higienista (OLIVEIRA, 2005). Mais do que um espaço para as crianças, as creches foram criadas para solucionar o problema das mães que necessitavam ingressar no mercado de trabalho na década de 70, com um papel limitador da escola, em que se tentava atender as demandas sociais e, se possível, solucioná-las. Podemos inferir que as 
necessidades de cuidado das crianças dão aos profissionais uma visão maternal, que tende a desqualificar esse profissional e a aproximá-lo da visão doméstica - a tia.

A força do método, como defendida pela clínica da atividade, pode ser verificada no desdobramento da intervenção, quando os Professores realizam as autofilmagens e aceitam colocar essas imagens em debate no coletivo. E a Professora Chris explicita essa força nos excertos a seguir:

Chris: [...] Eu achei que a gente ia levantar pontos 'olha aqui você fez essa atividade, poderia ser dessa e dessa forma, melhorar nisso e nisso', 'eu acho que essa sua postura deveria estar assim, assado'. Quando na verdade o que eu vi (aponta para o vídeo) gritando foi essa questão é... de corpo! Do que sou.... Do que sinto!

Interv.: ....Sabe o que você está sentindo...

Chris: Acho que todos deveriam ter essa oportunidade.

Interv: Que oportunidade?

Chris: De se ver assim ....

Em um terceiro movimento, a intervenção muda de contexto por solicitação das participantes. A Diretora se transferiu do CEI para uma EMEI, e nessa nova escola ela convida a Professora Claudia para atuar na EMEI como Vice-Diretora, pois esse é um cargo de confiança na Rede Municipal de São Paulo, o que permite à Diretora escolher o seu vice, que atua no Cargo de Assistente de Direção. O novo cargo implicava novas responsabilidades para a Professora Claudia, assim como o novo contexto se apresentava como um novo desafio para a Diretora Elaine. Desse modo, a Vice-Diretora expressou desejo de ser filmada novamente para discutir sua prática:

Vice-Diretora: Era bom quando você filmava a gente e podíamos pensar em nosso trabalho.

Diretora: Sim, vamos fazer! Mas dessa vez eu quero participar, da outra vez vocês me 'deixaram de fora', agora eu também quero filmar.

A Diretora, que não participou diretamente das discussões no $\mathrm{CEI}$, mas teve papel fundamental no suporte e na viabilização do processo com os Professores, concordou com o 
desdobramento da intervenção e pediu para participar. Desse modo, o foco se deslocou para o trabalho da Equipe Gestora.

O novo contexto representou um desafio para ambas, pois a EMEI atende crianças de $4 \mathrm{e}$ 5 anos desde 1988, tendo na gestão uma Diretora por 30 anos. Portanto, a mudança de gestão gerou certo desconforto. Além disso, a EMEI, além de atender crianças maiores, é também maior, pois acolhe cerca de 453 crianças e 53 funcionários.

Nessa nova etapa, a Diretora se observou no vídeo de sua ACS e, do mesmo modo que as Professoras, também se surpreendeu com sua imagem:

Dir.: Nossa, que séria! Ah, eu tô feliz de me ver séria! É difícil para mim, porque assim, o tempo todo brincando... difícil isso!

Interv.: Você queria ser séria? Por que você queria ser séria? Por que você está feliz de estar séria?

Dir.: Ahhh, porque tem hora que ficar mostrando os dentes ...

Interv.: Você acha que a posição de Diretora pede uma cara séria, é isso?

Dir.: Infelizmente, porque as pessoas confundem!

Interv.: Confundem o quê?

Dir.: Confundem, achando que podem falar qualquer coisa ... tem absurdo que você não pode falar para sua chefia, que me obriga a tomar atitude; na verdade, é essa liberdade que confunde: pode brincar, interagir, se respeitar, não consigo ser diferente, e o preço é esse, essa confusão...

Interv.: Que tipo de confusão?

Dir.: Por exemplo, a [falta] abonada, pela lei você solicita a abonada no dia seguinte que aconteceu alguma coisa que te impediu de ir trabalhar. A regra é vir trabalhar, o abono é uma exceção. Aí você tem lá um caso de um Professor que tem dois cargos, passou por um filho doente, ela está cansado, precisa simplesmente dormir, eu não posso falar 'ok a prefeitura vai te pagar um dia da semana para você dormir', aí o que eles pensam? 'Ela é legal, vou lá falar!' Não! Por exemplo, se falta sem avisar, ou se agenda, acha que pode falar qualquer coisa... 'ah eu vou fazer compras!'. Não! Aí fala: 'olha como ela é mentirosa, é tão legal, brinca com a gente o tempo todo, mas quando eu preciso me fala não!'. Difícil isso!

Esse segmento mostra o conflito da Diretora com as representações que tem de si (o lado pessoal) com aquelas que autoprescreve para si, bem como com as prescrições da atividade (impessoal), ou mesmo, com as representações que tem sobre os modos de agir (transpessoal), legitimados ao longo da história de sua profissão e dos funcionários. 
Interv.: Como é para você falar o NÃO?

Dir.: É difícil! Para mim até hoje é difícil dizer esse não, tem sete anos de gestão e ainda é difícil dizer esse não! Porque eu entendo esse cansaço! Eu me coloco no lugar da pessoa, trabalhar todos os dias das $7 \mathrm{~h}$ às $7 \mathrm{~h}$, com dois cargos, cheio de coisa para fazer, de repente um descanso até ajuda a pessoa a voltar e trabalhar... mas tudo é jogado nas costas do Diretor, por exemplo, se no dia que eu deixei alguém abonar, faltou mais alguém que foi ao médico e não veio, uma criança caiu e sofreu um acidente, aí[a turma] vai estar dividida, a primeira coisa que vão perguntar o que aconteceu, vão falar 'a sala estava cheia' 'e porque a sala estava cheia?' 'porque a Diretora deu [falta] abonada!' Aí vem tudo em cima da gente.

Podemos observar na frase da Diretora todos os implícitos que são suscitados: 'Vão perguntar o que aconteceu, vão falar 'a sala estava cheia' 'e por que a sala estava cheia?' 'porque a Diretora deu abonada!'. Podemos também inferir os sujeitos ocultos nas vozes que são postas em cena - 'quem vai perguntar?' A resposta nos mostra que ela sabe que existe uma supervisão acima dela a quem a Escola / Diretora se reporta, caso aconteça alguma intercorrência. Mas ela se reporta também ao próprio grupo, a outros Professores, e à própria comunidade, aos pais e responsáveis pelas crianças. Verifica-se o conflito vivenciado pela Diretora, que se vê entre o prescrito e o real da Atividade, colocando em cena o choque entre as dimensões pessoal, impessoal e interpessoal (CLOT, 2017), e isso configura, de fato, um conflito transpessoal.

Vemos que há subentendidos dessa atividade, uma memória coletiva da profissão, o que Clot (2010) denomina como "gênero de atividade". O gênero diz como as pessoas com quem trabalhamos devem ou não agir, e estas pressuposições genéricas são constituídas ao longo da história da profissão.

O gênero é, de algum modo, a parte subentendida da atividade, o que os trabalhadores de dado meio conhecem e observam, esperam e reconhecem, apreciam ou temem; o que lhes é comum, reunindo-os sob condições reais de vida; o que sabem que devem fazer, graças a uma comunidade de avaliações pressupostas, sem que seja necessário reespecificar a tarefa cada vez que ela se apresenta. É como uma "senha" conhecida somente por aqueles que pertencem a um mesmo horizonte social e profissional (CLOT, 2010, p.121-122). 
É uma memória produzida por aqueles que fazem ou fizeram o métier e foram, ao longo da história, construindo maneiras de se comportar, de dirigir a palavra, de realizar uma atividade, constituindo um repertório dos atos aceitáveis ou deslocados.

Essa dimensão transpessoal da atividade de trabalho na educação é afetada também pela estrutura de organização do trabalho na escola, que é hierarquizada, desde a origem dos cargos de gestão, e separa especialistas e Professores. Por mais que exista um discurso sobre a gestão democrática, a administração escolar é fortemente influenciada pela administração de empresas, perfeitamente imbricada no sistema capitalista e em suas contradições (GABOS, 2020; OLIVEIRA, 2005). Vemos, nos dizeres da gestora citados acima, a vivência dos conflitos inscritos na história desse trabalho.

Do mesmo modo, a Vice-Diretora faz suas observações a partir das imagens no confronto com a interveniente no momento da ACS. A vice apresenta com precisão a divisão de papéis da Equipe Gestora, destacando especialmente o seu próprio papel nessa equipe e a necessidade de alinhamento e integração entre elas.

Vice: Nessa hora [reunião] que eu acho legal é que as duas estão sentadas [Diretora e vice] e a gente não combinou, mas quem tem que estar no centro é a $C P$, isso é um...

Interv.: Ela que está apresentando...

Vice: $E$... eu acho! Isso que é o papel do vice, então o vice, ele está assim, ele é para o Diretor, mas tem momentos que pode ser para o coordenador e tem hora que pode ser para a secretaria. Então é... eu acho o momento de quem está, eu que estou como vice, é esse momento, cuidado para não tirar o que é da Sandra [CP] e o que é da Elaine [Diretora], em que momentos que a Claudia [eu] também pode se posicionar sem parecer que está invadindo... exemplo, alguns conflitos que acontecem aqui e que a Elaine está mediando. Né então? Em que momentos que a Claudia intervém para não tirar isso da Elaine, porque eu já tive esses momentos de presenciar, não aqui, mas como Professora, do vice sair um pouco mais e aí o grupo fala: nossa eu já sei quem manda, isso é chato, não é bacana.

Sua vivência de mais de dez anos como Professora lhe dá subsídios para compreender o que cabe ao Diretor, o que cabe ao Vice e a importância desse estreitamento frente ao grupo. Isso fica claro na afirmação que pauta sua ação, ao recordar falas que contestam a posição do Diretor e do Vice: 'já sei quem manda aqui'. Dando continuidade, a interveniente segue com a 
pergunta sobre o seu papel na EMEI, se isso está posto de forma clara e sem conflitos. A Professora é categórica nas suas colocações, como observamos a seguir.

Interv.: Então você acha que para você está claro seu papel?

Vice: Sim, sim... Eu tenho muito claro que... é a importância do Diretor, ele precisa mesmo desse vice... é o que eu falo para a Elaine, eu fico me imaginando, e para mim está sendo uma experiência riquíssima, eu fico imaginando o que é [ser] o Diretor na hora que ele assina, porque ele assina sozinho, como ele precisa ter alguém de confiança para falar: "olha, estou nesse meio e não estou conseguindo enxergar", assim como conversa a coordenação, assim como também o CP precisa desse apoio, não é? Esse, esse ... é como se fosse um meio entre gestor e $C P$, né?

Vemos nesses segmentos de fala da Vice-Diretora a vivência dos conflitos da dimensão interpessoal (CLOT, 2017); existe uma relação direta entre as funções e os papéis de cada uma em prol de uma construção coletiva do trabalho. O interpessoal, o trabalho coletivo, em que objetivos e estratégias são utilizadas conjuntamente, é posto em cena de forma enfática, é como se a Vice-Diretora reconhesse sua atividade espelhada nas necessidades do outro, num processo de busca de equilíbrio entre as práticas e as necessidades de cada ofício.

Nessa mesma direção, a Coordenadora apresenta suas reflexões frente às imagens videogravadas:

Interv.: É como você se vê?

Coord.: Sim, mas eu não queria ser assim, acho que eu sou mole demais, calma... eu queria ser assim como a Claudia [vice] e não consigo...

Interv.: Claudia como?

Coord.: A Claudia...

Interv.: Sim... mas o que da Claudia...

Coord.: Assim... como eu posso falar? Firme! Sabe assim... de se posicionar e não está nem aí para o que os outros vão pensar, vão achar e vão falar...

A Coordenadora afirma e reafirma, a partir do reconhecimento do modo de agir de sua colega (a vice), que a maneira como ela se posiciona frente ao grupo é pouco efetiva, pois sua postura 'calma', como ela destaca, dificulta a compreensão, por parte dos Professores, das ações e dos comportamentos esperados. 
Coord.: Eu sou calma, não gosto de confusão, tudo o que der para eu dar um jeitinho ... sabe ... para dar todo mundo assim em um ambiente agradável... eu... eu... isso é meu, eu já queria mudar, porque assim, tem situações que eu queria chegar, e este ano já estou fazendo mais isso, já... já consigo ter essa... não sei pode até ser a convivência de estar ouvindo a Claudia, né? [...] não sei... séria.... e eu assim com essa cara mole, mansa, quem vai ter medo, medo não, respeito! Então, eu queria ser mais firme, eu sou assim mole [...] Interv.: Mas você acha que se você fosse dura ia ser diferente? Coord.: Acho que sim, porque impõe respeito...eu sou mole.... [...]

Nesse momento, a Coordenadora para e pensa por alguns instantes, revê a imagem no vídeo e então afirma:

Coord.: Não... assim... acho que desse jeito dá, porque eu tenho conseguido com elas...

Interv.: Então? Precisa ser dura?

Coord.: É... não precisa ser dura, olha está vendo, nunca parei para pensar $\operatorname{assim...}$

Observando-se, a Coordenadora põe em cena conflitos da dimensão transpessoal (CLOT, 2017) que evidenciam as vivências do seu trabalho e o que se espera do seu papel profissional. Ao rever a imagem, a Coordenadora revê também seu posicionamento, que está ancorado no que ela acredita ser o esperado genérico de sua atividade. Há um conflito entre seu modo de ser, legitimado ao longo do tempo. Mas, como nos ensina Clot (2010, p.126), os gêneros são relativamente estabilizados, "o estilo individual é, antes de mais nada, a transformação dos gêneros na história real das atividades no momento de agir em função das circunstâncias...". A cada nova realização, a cada sujeito que inscreve sua atividade no elo ininterrupto de outras atividades, o gênero pode ser renovado, pois o sujeito sempre coloca nele algo de seu. Vemos que a autoconfrontação tornou o gênero visível e discutível, o que revela a potencialidade desse dispositivo metodológico, possibilitando aos sujeitos ampliar seu poder de agir.

Ninguém recebe o legado de uma experiência pronta para usar; em vez disso, cada um assume um dado lugar na corrente das atividades. De modo mais preciso, a atividade pessoal só é construída nessa e contra essa corrente, mediante a apropriação do gênero. Mas este último, longe de ser um sistema abstrato de normas, sempre igual a si mesmo vê-se absorvido na ação de um coletivo, dilacerado pelas contradições vivas de um dado meio de trabalho, para

Periódico Horizontes - USF - Itatiba, SP - Brasil - e021040 
eventualmente voltar, saturado de variantes e prenhe de nuanças, com uma estabilidade que é igualmente sempre provisória. Os gêneros são no final a integral dos equívocos que sua história neles permitiu persistir. A análise do trabalho os desloca. Dispor dos gêneros é algo que sempre requer que o sujeito neles introduza algo de seu (CLOT, 2006, p.203).

Vemos, em todos os segmentos apresentados, a configuração da dimensão transpessoal, como discutido por Clot (2017). Os profissionais, a partir do dispositivo de AC, estão refletindo e discutindo para se reconhecer no modo de agir, tomando como base o prescrito, implícito e explicitamente legitimado pelo coletivo da educação infantil, isto é, pelo gênero da atividade da educação.

\section{Considerações Finais}

Dado o exposto, observamos que as Professoras experimentam a docência na Educação Infantil de formas diversas: a Professora Chris, brava, não acha adequada essa postura para esse segmento; por outro lado, o excesso de doçura da Professora Rose também não é visto como adequado. Fica, então, a questão de qual seria a cara, a face desse profissional que atuará com crianças pequenas. Ousamos afirmar que não há um estereótipo a ser seguido, um modelo de profissional para determinado segmento, porém há que se respeitar e atender a criança em suas singularidades. Vemos isso, de certa forma, na atividade do Professor Mário, que usa sua experiência para dirigir sua atividade.

Dando continuidade, observamos que a Equipe Gestora vivencia conflitos relacionados com o próprio papel, mas também com o próprio significado de ser Diretora, Vice e Coordenadora na Educação Infantil, e podemos dizer que para cada uma delas há um conflito e um desafio relacionado com essa posição e com as decisões e os posicionamentos assumidos. Desse modo, observamos a Diretora vivenciando o conflito, ao entender a posição dos Professores, mas com o desafio de precisar seguir as prescrições; a Vice-Diretora vivencia o conflito de saber como e quando se posicionar, mas tem o desafio de não entrar na função da Diretora ou da Coordenadora Pedagógica; e, por fim, a Coordenadora vive o conflito de acreditar 
que precisa ser mais firme, mais dura com o desafio de posicionar-se, sem causar mal-estar na relação com as Professoras.

A ideia das quatro dimensões do métier (CLOT, 2010) pode nos ajudar a pensar nos conflitos vividos pelos profissionais da educação, conflitos que têm relação com as prescrições (oficiais e oficiosas), ou seja, com a dimensão impessoal do trabalho, mas também com a dimensão transpessoal, com a história coletiva, com os esperados de cada atividade, que vão sendo configurados no dia a dia do exercício da profissão. Há ainda os conflitos, como vimos, na dimensão interpessoal e pessoal, pois cada sujeito se insere na história coletiva da atividade, com suas especificidades e características pessoais, que podem entrar em conflito tanto com a dimensão genérica da profissão, quanto com a dimensão pessoal do colega de trabalho e com os diferentes modos de pensar e agir.

\section{Referências}

AMIGUES, R. Trabalho do professor e trabalho de ensino. In: MACHADO, A. R. (org.). O ensino como trabalho: uma abordagem discursiva. Trad. Anna Rachel Machado. Londrina: Eduel, 2004. p.35-53.

BAKHTIN, M. (VOLOCHINOV). Marxismo e filosofia da linguagem. São Paulo: Editora Hucitec, 6. ed., 1992.

BAKHTIN, M. Estética da criação verbal. São Paulo: Martins Fontes, 2003.

BARRICELLI, E. A reconfiguração pelos professores da proposta curricular de educação infantil. 2017, 324f. Dissertação (Mestrado em Linguística Aplicada) - Pontifícia Universidade Católica, São Paulo, 2007.

BARRICELLI, E. Transformações e conflitos no processo de elaboração de difusão e de utilização de instruções oficiais de educação infantil: um estudo genealógico. 2012. 210f.Tese (Doutorado em Linguística Aplicada) - Pontifícia Universidade Católica, São Paulo, 2012.

BARRICELLI, E.; ANJOS, D. Autoconfrontação: interação pesquisador-professor revelando sentido para o discurso do professor. Revista virtual de estudos da linguagem, v.18, p.66-82, 2020. Disponível em: http://www.revel.inf.br/files/875feec13da1afbd666056701d77670f.pdf. Acesso em: 01 jun. 2021.

BRASIL. Lei de diretrizes e bases da educacional - LDB, Lei 9394/96. Brasília: MEC, 1996. 
BRASIL. Ministério da Educação e do Desporto. Secretaria de Educação Fundamental.

Referencial curricular nacional para a educação infantil. Ministério da Educação e do Desporto, Secretaria de Educação Fundamental. Brasília: MEC/SEF, 1997.

BRASIL. Ministério da Educação. Base nacional comum curricular (BNCC). Brasília: MEC, 2018.

BUNZEN, C. A fabricação da disciplina escolar português. Rev.Diálogo Educ., Curitiba, v.11, n.34, p.885-911, set./dez. 2011.

CLOT, Y. La fonction psychologique du travail. Paris: Presses Universitaires de France, 1999.

CLOT, Y. L'auto-confrontation croisée en analyse du travail: I'apport de la théorie bakhtinienne du dialogue. In: FILLIETTAZ, L.; BRONCKART, J. P.(dir.). L'analyse des actions et des discours en situation de travail. Louvain-La-Neuve: Peeters, 2005. p.37-54.

CLOT, Y. A função psicológica do trabalho. Petrópolis: Vozes, 2006.

CLOT, Y. A função psicológica do trabalho. 2. ed. Petrópolis: Vozes, 2007.

CLOT, Y. Travail et pouvoir d'agir. Paris: Presses Universitaires de France, 2008.

CLOT, Y. Trabalho e poder de agir. Belo Horizonte: FabreFactum, 2010.

CLOT, Y. Vygotski: a consciência como relação. Psicologia \& Sociedade, n.26, n.especial 2, p.124-139, 2014.

CLOT, Y. Clínica da atividade. Horizontes, v.35, n.3, p.18-2, 2017. Disponível em: https://doi.org/10.24933/horizontes.v35i3.526. Acesso em: 01 jun. 2021.

CLOT, Y. et al. Les entretiens en autoconfrontation croisée: une méthode en clinique de l'activité. Education Permanent, Paris, n.146, p.17-27, 2001.

CLOT, Y.; FAÏTA, D. Gêneros e estilos em análise do trabalho: conceitos e métodos. Trabalho \& Educação, v.25, n.2, p.33-60, 2016. Disponível em:

https://periodicos.ufmg.br/index.php/trabedu/article/view/9555. Acesso em: 20 jul. 2021.

DIOLINA, K. Quem ensina, aprende a vencer os desafios da profissão: o papel do coletivo. 2016. 238f. Tese (Doutorado em Linguística Aplicada e Estudos da Linguagem) - Pontifícia Universidade Católica de São Paulo: São Paulo, 2016.

FABRÍCIO, B. F. Linguística aplicada como espaço de desaprendizagem: redescrições em curso. In: FABRÍCIO, B. F.; LOPES, L. P. M. (orgs.). Por uma linguística aplicada indisciplinar. São Paulo: Parábola, 2006. p.45-65. 
GABOS, A. A experiência da gestão no retorno à sala de aula e as implicações ao trabalho docente em suas diferentes dimensões. 2020. 109f. Dissertação (Mestrado em Educação) Unicamp, Campinas, 2020.

KOSTULSKI, K. et al. L'horizon incertain de la transformation en clinique de l'activité: une intervention dans le champ de l'éducation surveillée. Activités, v.8, n.1, p.129-145, 2011. Disponível em: http://www.activites.org/v8n1/v8n1.pdf. Acesso em: 01 jun. 2021.

LOUSADA, E. G.; DANTAS-LONGHI, S. M. Vozes em confronto: o papel das entrevistas de confrontação no desenvolvimento do professor e de sua atividade de trabalho. In: NASCIMENTO, E. L.; ROJO, R. H. R. (orgs.). Gêneros de texto/discurso e os desafios da contemporaneidade. Campinas: Pontes, 2014. p.143-166.

OLIVEIRA, R. M. A secretaria municipal de educação de Campinas (2001- 2004): contribuições para o entendimento da Escola Viva. 2005. 520f. Tese (Doutorado em Educação) Universidade Estadual de Campinas - Unicamp, Campinas, 2005.

VIGOTSKI, L. S. A construção do pensamento e da linguagem. Trad. Paulo Bezerra. São Paulo: Martins Fontes, 2001.

VIGOTSKI, L. S. A formação social da mente. São Paulo: Martins Fontes, 2003.

VIGOTSKI, L. S. Imaginação e criação na infância. São Paulo: Ática, 2009.

Recebido em maio 2021.

Aprovado em julho 2021. 